\title{
PENERAPAN PEMBELAJARAN TGT DENGAN AKUNTAPOLI UNTUK MENINGKATKAN KEAKTIFAN BELAJAR AKUNTANSI SISWA MAN YOGYAKARTA III
}

\section{TGT LEARNING WITH APPLICATION TO INCREASE ACTIVITY AKUNTAPOLI ACCOUNTING STUDENT LEARNING MAN YOGYAKARTA III}

\author{
Oleh : \\ Irfan Dwi Jayanto \\ Prodi Pendidikan Akuntansi Universitas Negeri Yogyakarta \\ Irfan.semangat@gmail.com
}

\section{Sukirno}

StafPengajar Jurusan P. Akuntansi Universitas Negeri Yogyakarta

\begin{abstract}
Abstrak
Penelitian Tindakan Kelas ini bertujuan untuk meningkatkan Keaktifan Belajar Akuntansi Siswa Kelas XI IPS 3 MAN Yogyakarta III Tahun Ajaran 2012/2013 melalui Penerapan Metode Pembelajaran Kooperatif Teknik TGT dengan Bantuan Media AkuntaPoli. Subjek penelitian adalah siswa kelas XI IPS 3 MAN Yogyakarta III sejumlah 27 siswa. Instrumen penelitian meliputi lembar observasi Keaktifan Belajar Akuntansi, serta catatan lapangan. Analisis data yang digunakan adalah analisis data deskripstif dengan persentase. Hasil penelitian menunjukkan bahwa Penerapan Metode Pembelajaran Kooperatif Teknik TGT dengan bantuan Media AkuntaPoli dapat Meningkatkan Keaktifan Belajar Akuntansi Siswa Kelas XI IPS 3 MAN Yogyakarta III Tahun Ajaran 2012/2013. Dibuktikan dengan adanya peningkatan disetiap indikator Keaktifan Belajar Akuntansi dari siklus I ke siklus II. Peningkatan skor rata-rata Keaktifan Belajar Akuntansi sebesar 14,08\% (relatif) dan 11,109\% (absolut), berasal dari skor ratarata Keaktifan Belajar Akuntansi siklus I 78,891\% menjadi 90\% (siklus II).
\end{abstract}

Kata Kunci : Metode Pembelajaran Kooperatif Teknik TGT , Media Akunta Poli, Keaktifan Belajar Akuntansi

\section{Abstract}

Classroom Action Research aims to improve Learning Accounting Student Activity Class XI IPS 3 MAN Yogyakarta III Academic Year 2012/2013 through the Application of Cooperative Learning Methods to Help Media Techniques AkuntaPoli TGT. The subjects were students of class XI IPS 3 MAN Yogyakarta III some 27 students. Research instruments include observation sheets ActivityLearning Accounting, as well as field notes. Data analysis is a data analysis deskripstif with percentages. The results showed that the application of Cooperative Learning Methods TGT technique with the help of AkuntaPoli Media Can Improve Student ActivityLearning Accounting Class XI IPS 3 MAN Yogyakarta III Academic Year 2012/2013. Evidenced by an increase in each 
indicator Being active Learning Accounting from cycle I to cycle II. Increase in the average score of 14.08 ActivityLearning Accounting\% (relative) and $11.109 \%$ (absolute), derived from the average score of the first cycleBeing active Learning Accounting $78.891 \%$ to $90 \%$ (cycle II).

Keywords : Cooperative Learning Methods TGT Techniques, Media AkuntaPoli, ActivityLearning Accounting

\section{A. PENDAHULUAN}

Dalam Undang-undang Nomor 20 tahun 2003 tentang Sistem Pendidikan Nasional, Bab I Pasal I ayat (1) dikemukakan bahwa; Sebagai usaha sadar dan terencana untuk mewujudkan suasana belajar dan proses pembelajaran agar peserta didik secara aktif mengembangkan potensi dirinya untuk memiliki kekuatan spiritual keagamaan, pengendalian diri, kepribadian, kecerdasan, akhlak mulia, serta ketrampilan yang diperlukan dirinya, masyarakat bangsa dan negara.

Keberhasilan tujuan pendidikan akan terwujud apabila proses pembelajaran dapat berlangsung secara efektif. Pembelajaran yang efektif dipengaruhi oleh dua faktor, yaitu faktor eksternal dan internal (Nana Sudjana, 2006: 2).

Pembelajaran efektif akan tercapai apabila didukung oleh komponenkomponen pembelajaran di dalamnya. Menurut Wina taputra (2007 : 2) terdapat 5 komponen dalam mendukung pembelajaran dapat berlangsung dengan efektif yaitu; tujuan pembelajaran, guru, siswa, kegiatan pemebelajaran, danevaluasi. Guru dan siswa merupakan komponen terpenting dalam pembelajaran, karena pembelajaran pada hakikatnya hubungan sebab-akibat, dan guru sebagai figur sentral mampu menetapkan strategi pembelajaran yang tepat sehingga dapat mendorong terjadinya perbuatan belajar siswa yang aktif, produktif, dan efisien.

Keaktifan Belajar Akuntansi merupakan salah satu faktor penting dalam mencapai keberhasilan pembelajaran siswa yang telah direncanakan oleh guru. Menurut Sardiman, A.M (2012: 95-97), aktivitas merupakan aspek terpenting dalam belajar karena pada hakikatnya belajar adalah suatu kegiatan. Tidak ada belajar apabila tidak ada aktivitas yang dilakukan. Nasution (2000: 90) Belajar adalah berbuat, bereaksi, menjalani, mengalami, tanpa aktivitas proses belajar siswa tidak akan menghasilkan sesuatu yang maksimal. Akuntansi adalah mata pelajaran yang diberikan jam lebih di setiap sekolah untuk jurusan IPS. Sampai saat ini akuntansi masih dianggap mata pelajaran yang sulit, membosankan. Selain mempunyai sifat yang abstrak, pemahaman konsep akuntansi yang baik sangatlah diperlukan untuk memahami konsep yang baru diperlukan prasyarat pemahaman konsep sebelumnya, serta latihan soal-soal akuntansi yang terus menerus membutuhkan ketelitian yang luar biasa menyebabkan peserta didik sendiri akan merasa bosan di kemudian harinya. Oleh karena itu Keaktifan Belajar Akuntansi 
perlu dibangun guru untuk menghasilkan pembelajaran yang efektif dan berkualitas.

Peneliti mengadakan observasi saat pelajaran akuntansi di kelas XI IPS 3 MAN Yogyakarta III untuk memperoleh gambaran kondisi siswa pada saat proses belajar akuntansi berlangsung. Kegiatan KBM yang dilaksanakan masih menggunakan metode ceramah dan latihan. Keaktifan Belajar Akuntansi siswa menjadi menurun saat guru menggunakan metode pembelajaran tersebut. Dibuktikan dengan siswa yang tidur saat KBM berlangsung, bercanda dengan teman sebangku, tidak mendengarkan penjelasan guru, tidak mengerjakan tugas yang telah diberikan oleh guru. Jika kondisi tersebut terus terjadi, dikhawatirkan akan menurunkan keberhasilan proses pembelajaran.

WinaSanjaya (2010: 92-93) menyebutkan masalah yang sering timbul dalam proses belajar mengajar adalah guru hanya menggunakan komunikasi satu arah sehingga guru tidak berusaha mengajak siswa untuk berpikir. Oleh karena itu perlunya sebuah inovasi strategi pembelajaran yang dilakukan oleh guru dengan lebih menganggap siswa sebagai subjek dan bukan objek lagi. Agar pembelajaran nantinya dapat berlangsung dua arah. Strategi Pembelajaran Kooperatif merupakan strategi pembelajaran yang memungkinkan siswa belajar secara aktif dan partisipatif. Ada berbagai teknik dalam metode cooperative learning, salah satunya adalah Metode Pembelajaran Kooperatif Teknik Teams Games Tournaments (TGT). Teknik ini dapat mengurangi ketergantungan siswa kepada guru, mengembangkan kemampuan mengungkapkan ide dan gagasan, membantu memberdayakan siswa lebih bertanggung jawab dalam belajar, meningkatkan keaktifan belajar siswa (Wina Sanjaya, 2010: 240-250). Inovasi bantuan media Akunta Poli dapat melengkapi strategi tersebut untuk meningkatkan keaktifan siswa. Aktivitas belajar dengan permainan yang dirancang dalam Metode Pembelajaran Kooperatif Teknik Teams Games Tournaments (TGT) memungkinkan siswa dapat belajar lebih rileks di samping menumbuhkan tanggung jawab, kerjasama, persaingan sehat dan Keaktifan Belajar Akuntansi akan meningkat.

Peneliti memandang bahwa dengan permasalahan yang ada, perlu diteliti melalui Penerapan Metode Pembelajaran Kooperatif Teknik Teams Games Tournaments (TGT) dengan Bantuan Media AkuntaPoli (Akuntansi-Monopoli) untuk Meningkatkan Keaktifan Belajar Akuntansi Siswa Kelas XI IPS 3 MAN Yogyakarta III Tahun Ajaran 2012/2013, sehingga keberhasilan pembelajaran siswa dapat telah direncanakan guru tercapai 


\section{B. METODE PENELITIAN}

\section{Jenis Penelitian}

Jenis penelitian yang digunakan adalah PTK. Penelitian ini bersifat partisipasif kolaboratif.

\section{Waktu dan Tempat Penelitian}

Penelitian ini dilaksanakan di MAN YOGYAKARTA III yang berlokasi di Jalan Magelang KM.4, Sinduadi,Mlati, Sleman. Penelitian dilaksanakan pada bulan April 2013-Juli 2013.

\section{Target/Subjek Penelitian}

Target/subjek penelitian adalah siswa kelas XI IPS 3 MAN YOGYAKARTA III yang berjumlah 27 siswa.

\section{Data, Instrumen, dan Teknik Pengumpulan}

a) Data

Dalam penelitian ini, teknik pengumpulan data dilakukan dengan menggunakan;

1) Observasi Partisipasif

Observasi partisipatif dalam penelitian ini dilakukan dengan mengikuti pembelajaran, untuk memperoleh data mengenai pelaksanaan pembelajaran, penggunaan teknik pembelajaran, dan aktivitas yang dilakukan siswa. Peneliti dibantu oleh 2 orang observer tetapi melakukan tugas observasi yang berbeda untuk mengamati Keaktifan Belajar Akuntansi.

2) CatatanLapangan

Catatan lapangan dibuat oleh dua orang observer yang digunakan untuk mendapatkan data tentang situasi, kondisi, dan aktivitas guru serta siswa selama proses pembelajaran dengan penerapan Pembelajaran Teknik TGT dengan Bantuan Media AkuntaPoli.

\section{b) Instrument Penelitian}

1) PedomanObservasi

Pedoman observasi Keaktifan Belajar Akuntansi berisi pedoman pengamatan aktivitas yang terjadi selama pembelajaran di dalam kelas. Indikator Keaktifan Belajar Akuntansi yang akan ditelitiialah:

Tabel 1.Kisi-Kisi Observasi Keaktifan Belajar Akuntansi

\begin{tabular}{|c|c|l|}
\hline No & \multicolumn{1}{|c|}{ Keaktifan } & \multicolumn{1}{|c|}{ Indikator } \\
\hline 1 & \multirow{2}{*}{ Visual } & $\begin{array}{l}\text { Siswa memperhatikan penjelasan guru atau } \\
\text { teman }\end{array}$ \\
\cline { 3 - 4 } 2 & & $\begin{array}{l}\text { Siswa membaca buku/materi Akuntansi } \\
\text { dari guru }\end{array}$ \\
\hline 3 & & Siswa mengajukan pertanyaan kepada guru \\
\hline
\end{tabular}


Jurnal Pendidikan Akuntansi Indonesia, Vol. XI, No. 2, Tahun 2013 Irfan Dwi Jayanto \& Sukirno

$1-10$

\begin{tabular}{|c|c|c|}
\hline No & Keaktifan & Indikator \\
\hline & \multirow[b]{3}{*}{ Lisan } & saat KBM/siswa saat kegiatan tim. \\
\hline 4 & & $\begin{array}{l}\text { Siswa memberi jawaban, saran, pendapat, } \\
\text { atau komentar kepada guru/teman. }\end{array}$ \\
\hline 5 & & Siswa melakukan diskusi kelompok \\
\hline 6 & \multirow[b]{2}{*}{ Mendengar } & $\begin{array}{l}\text { Siswa mendengarkan penjelasan guru saat } \\
\text { kegiatan presentasi. }\end{array}$ \\
\hline 7 & & $\begin{array}{l}\text { Siswa mendengarkan temannya saat } \\
\text { kegiatan belajar tim dan games- } \\
\text { tournament. }\end{array}$ \\
\hline 8 & \multirow{3}{*}{$\begin{array}{l}\text { Menu } \\
\text { lis }\end{array}$} & $\begin{array}{l}\text { Siswa mencatat materi yang disampaikan } \\
\text { oleh guru. }\end{array}$ \\
\hline 9 & & $\begin{array}{l}\text { Siswa mengerjakan latihan yang diberikan } \\
\text { guru dalam kegiatan belajar tim. }\end{array}$ \\
\hline 10 & & $\begin{array}{l}\text { Siswa menjawab pertanyaan (menulis) saat } \\
\text { games-tournament dengan media } \\
\text { AkuntaPoli. }\end{array}$ \\
\hline
\end{tabular}

Kisi-kisi observasi Keaktifan Belajar Akuntansi merujuk pada teori keaktifan belajar Paul D. Dierich (dalam Ahmad Rohani, 2004:9).

2) CatatanLapangan

Catatan lapangan berupa formulir yang digunakan sebagai catatan berbagai aspek dalam pelaksanaan pembelajaran di kelas, suasana kelas, pengelolaan kelas yang dilakukan guru, interaksi yang dilakukan guru dan siswa.

c) TeknikAnalisis Data

Teknik analisis data yang digunakan dalam penelitian ini adalah Analisis Data Deskriptif dengan Persentase. Analisis ini dilakukan dengan

1) Mengolah skor Keaktifan Belajar Akuntansi

(a) Membuat kategori penyekoran untuk Keaktifan Belajar Akuntansi

(b) Mengitung dan menjumlahkan skor keaktifan belajar pada tiap siswa

(c) Menghitung dan menjumlahkan skor untuk masing-masing Keaktifan Belajar Akuntansi yang diamati

(d) Menghitung skor Keaktifan Belajar Akuntansi pada setiap aspek yang diamati dengan rumus : jumlahskorpadasetiapaspek skormaksimum

(Sugiyono, 2012: 144)

(e) Menghitung peningkatan persentase Keaktifan Belajar Akuntansi dengan rumus :

(1) Peningkatan persentase relatif 


$$
\frac{B-A}{A} \times 100 \%
$$

Keterangan:

B: Persentase Skor Siklus II tiap indikator

A: Persentase Skor Siklus I tiap indikator

(2) Peningkatan persentase absolut

$$
B-A
$$

Keterangan:

B: Persentase Skor Siklus II tiap indikator

A: Persentase Skor Siklus I tiap indikator

(f) Menghitung persentase skor rata-rata Keaktifan Belajar Akuntansi dengan cara membagi skor total Keaktifan Belajar Akuntansi dengan jumlah indikator yang digunakan

2) Menyajikan data

Setelah data Keaktifan Belajar Akuntansi diolah, data ditampilkan secara sederhana dan disajikan ke dalam bentuk tabel dan grafik, sehingga lebih mudah dipahami.

3) Menarik kesimpulan

Penarikan kesimpulan dilakukan untuk menjawab rumusan masalah yang diajukan pada awal penelitian.

\section{HASIL PENELITIAN DAN PEMBAHASAN}

1. Siklus I

Penelitian Siklus I dilaksanakan pada hari Rabu tanggal 15 Mei 2013, adapun hasil dari penelitiannya yaitu:

Tabel 2. Skor Indikator Keaktifan Belajar Akuntansi Siklus I

\begin{tabular}{|l|l|l|}
\hline No & Indikator & Persentase \\
\hline $\mathbf{1}$ & Siswa memperhatikan penjelasan guru atau teman & 75,93 \\
\hline $\mathbf{2}$ & Siswa membaca buku/materi Akuntansi dari guru & 77,78 \\
\hline $\mathbf{3}$ & $\begin{array}{l}\text { Siswa mengajukan pertanyaan kepada guru saat } \\
\text { KBM/siswa saat kegiatan tim. }\end{array}$ & 75,93 \\
\hline $\mathbf{4}$ & $\begin{array}{l}\text { Siswa memberi jawaban, saran, pendapat, atau } \\
\text { komentar kepada guru/teman. }\end{array}$ & 77,78 \\
\hline $\mathbf{5}$ & Siswa melakukan diskusi kelompok & 75,93 \\
\hline $\mathbf{6}$ & $\begin{array}{l}\text { Siswa mendengarkan penjelasan guru saat kegiatan } \\
\text { presentasi. }\end{array}$ & 79,63 \\
\hline $\mathbf{7}$ & $\begin{array}{l}\text { Siswa mendengarkan temannya saat kegiatan belajar } \\
\text { tim dan games-tournament. }\end{array}$ & 79,63 \\
\hline $\mathbf{8}$ & Siswa mencatat materi yang disampaikan oleh guru. & 77,78 \\
\hline $\mathbf{9}$ & $\begin{array}{l}\text { Siswa mengerjakan latihan yang diberikan guru } \\
\text { dalam kegiatan belajar tim. }\end{array}$ & 83,33 \\
\hline $\mathbf{1 0}$ & $\begin{array}{l}\text { Siswa menjawab pertanyaan (menulis) saat games- } \\
\text { tournament dengan media AkuntaPoli. }\end{array}$ & 85,19 \\
\hline Skor Rata-rata Siklus I & 78,89 \\
\hline
\end{tabular}

Sumber : Data Primer yang Diolah 
Skor total rata-rata Keaktifan Belajar Akuntansi Siklus I diatas 75\%, sehingga dikatakan berhasil. Perlu melakukan refleksi terhadap hasil Siklus I untuk perbaikan di Siklus selanjutnya.

\section{Siklus II}

Tabel 3.Skor Indikator Keaktifan Belajar Akuntansi Siklus II

\begin{tabular}{|l|l|c|}
\hline No & Indikator & Persentase \\
\hline 1 & Siswa memperhatikan penjelasan guru atau teman. & 92,59 \\
\hline 2 & Siswa membaca buku/materi Akuntansi dari guru. & 90,74 \\
\hline 3 & $\begin{array}{l}\text { Siswa mengajukan pertanyaan kepada guru saat } \\
\text { KBM/siswa saat kegiatan tim. }\end{array}$ & 85,19 \\
\hline 4 & $\begin{array}{l}\text { Siswa memberi jawaban, saran, pendapat, atau } \\
\text { komentar kepada guru/teman. }\end{array}$ & 87,04 \\
\hline 5 & Siswa melakukan diskusi kelompok. & 87,04 \\
\hline 6 & $\begin{array}{l}\text { Siswa mendengarkan penjelasan guru saat kegiatan } \\
\text { presentasi. }\end{array}$ & 88,89 \\
\hline 7 & $\begin{array}{l}\text { Siswa mendengarkan temannya saat kegiatan } \\
\text { belajar tim dan games-tournament. }\end{array}$ & 88,89 \\
\hline 8 & $\begin{array}{l}\text { Siswa mencatat materi yang disampaikan oleh } \\
\text { guru. }\end{array}$ & 92,59 \\
\hline 9 & $\begin{array}{l}\text { Siswa mengerjakan latihan yang diberikan guru } \\
\text { dalam kegiatan belajar tim. }\end{array}$ & 92,59 \\
\hline 10 & $\begin{array}{l}\text { Siswa menjawab pertanyaan (menulis) saat games- } \\
\text { turnament dengan media AkuntaPoli. }\end{array}$ & 94,44 \\
\hline Skor Rata-rata Siklus II & 90 \\
\hline
\end{tabular}

Sumber : Data Primer yang Diolah

Terdapat peningkatan skor persentase signifikan dari Siklus I. Skor total rata-rata persentase Siklus II jauh di atas $75 \%$, sehingga penelitian di Siklus II dapat dikatakan berhasil.

Hasil penelitian ini sangat menguatkan bahwa metode pembelajaran TGT dengan Media Akunta Poli dapat meningkatkan Keaktifan Belajar Akuntansi Siswa Kelas XI IPS 3 MAN YOGYAKARTA III.

\section{Pembahasan}

Tabel 4. Perbandingan Skor Indikator Keaktifan Belajar Akuntansi Siklus I dan II

\begin{tabular}{|l|c|c|c|c|}
\hline \multirow{2}{*}{ No } & \multicolumn{2}{|c|}{ Skor } & \multicolumn{2}{c|}{ Peningkatan } \\
\cline { 2 - 5 } & Siklus I & Siklus II & Absolut & Relatif \\
\hline 1 & 75,93 & 92,59 & 16,66 & 21,94 \\
\hline 2 & 77,78 & 90,74 & 12,96 & 16,66 \\
\hline 3 & 75,93 & 85,19 & 9,26 & 12,20 \\
\hline 4 & 77,78 & 87,04 & 9,26 & 11,91 \\
\hline 5 & 75,93 & 87,04 & 11,11 & 14,63 \\
\hline 6 & 79,63 & 88,89 & 9,26 & 11,63 \\
\hline 7 & 79,63 & 88.89 & 9.26 & 11,63 \\
\hline 8 & 77,78 & 92,59 & 14,81 & 19,04 \\
\hline 9 & 83,33 & 92,59 & 9,26 & 11,11 \\
\hline
\end{tabular}


Jurnal Pendidikan Akuntansi Indonesia, Vol. XI, No. 2, Tahun 2013 Irfan Dwi Jayanto \& Sukirno

$1-10$

\begin{tabular}{|c|c|c|c|c|}
\hline \multirow{2}{*}{ No } & \multicolumn{2}{|c|}{ Skor } & \multicolumn{2}{c|}{ Peningkatan } \\
\cline { 2 - 5 } & Siklus I & Siklus II & Absolut & Relatif \\
\hline 10 & 85,19 & 94,44 & 9,25 & 10,86 \\
\hline $\begin{array}{c}\text { Rata- } \\
\text { rata }\end{array}$ & 78,891 & 90 & 11,109 & 14,08 \\
\hline
\end{tabular}

Sumber: Data primer yang diolah

Keterangan:

No :Menunjukan indicator Keaktifan Belajar Akuntansi.

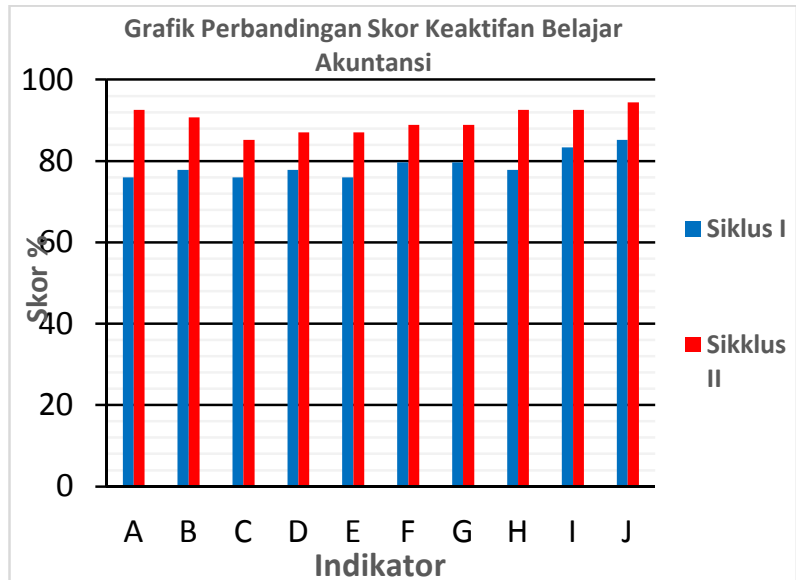

Gambar 1. Grafik perbandingan skor Siklus I dan Siklus II

Keterangan:

$\mathrm{A}=$ Siswa memperhatikan penjelasan guru atau teman.

$\mathrm{B}=$ Siswa membaca buku/materi Akuntansi dari guru.

$\mathrm{C}=$ Siswamengajukan pertanyaan kepada guru saat $\mathrm{KBM} /$ siswa saat kegiatan tim.

$\mathrm{D}=$ Siswa memberija waban, saran, pendapat, atau komentar kepada guru / teman.

$\mathrm{E}=$ Siswa melakukan diskusi kelompok.

$\mathrm{F}=$ Siswa mendengarkan penjelasan guru saat kegiatan presentasi.

$\mathrm{G}=$ Siswa mendengarkan temannya saat kegiatan belajar tim dan gamestournament.

$\mathrm{H}=$ Siswa mencatat materi yang disampaikan oleh guru.

I = Siswa mengerjakan latihan yang diberikan guru dalam kegiatan belajar tim.

$\mathrm{J}=$ Siswa menjawab pertanyaan (menulis) saat games-tournament dengan media Akunta Poli.

Tabel 4dangambar 1 memperlihatkan perbandingan skor Keaktifan Belajar Akuntansi dari siklus I ke siklus II yang mengalami peningkatan, peningkatan persentase tertinggi di peningkatan relatif terjadi pada uraian indikator siswa memperhatikan penjelasan guru atau teman yang mencapai $21,94 \%$ dan peningkatan persentase terendah pada uraian indikator siswa menjawab pertanyaan (menulis) saatgames-tournament dengan media AkuntaPoli yang mencapai $10,86 \%$. Sedangkan menurut peningkatan 
absolut, terjadi pula peningkatan persentase tertinggi terjadi pada uraian indikator siswa memperhatikan penjelasan guru atau teman yang mencapai $16,66 \%$ dan peningkatan persentase terendah pada uraian indikator siswa menjawab pertanyaan (menulis) saatgamestournamentdengan media AkuntaPoli yang mencapai 9,25\%.

\section{PENUTUP}

\section{Kesimpulan}

a) Penerapan Metode Pembelajaran Kooperatif Teknik Teams Games Tournament dengan Bantuan Media Akunta Poli dapat Meningkatkan Keaktifan Belajar Akuntansi SiswaKelas XI IPS 3 MAN Yogyakarta III TahunAjaran 2012/2013.

b) Mengetahui penerapan pembelajaran Kooperatif TGT yang terdiridari 4 tahap yaitu; presentasi kelas, belajar tim, games-tournament, serta penghargaan tim.

c) Peningkatkan Keaktifan Belajar Akuntansi dengan menerapkan Metode TGT dibuktikan dengan skor total rata-rata Keaktifan Belajar Akuntansi lebih dari $75 \%$.Skor total rata-rata Keaktifan Belajar Akuntansi sebesar 14,08\% (relatif) dan 11,109\% (absolut).

\section{Saran}

a) Bagi Guru

1) Perlunya inovasi dalam pelaksanaan proses pembelajaran.

2) Guru dapat menerapkan Pembelajaran Kooperatif Teknik Teams Games Tournament dengan Bantuan Media Akunta Poli (Akuntansi-Monopoli) sebagai salah satu alternatif pembelajaran untuk meningkatkan Keaktifan Belajar Akuntansi

3) Pentingnya kemampuan seorang guru dalam mengelola kelas dan waktu.

b) Bagi Penelitian Selanjutnya

1) Dapat mengembangkan media Akunta Poli untuk ubah dalam bentuk digital agar sesuai dengan tuntutan jaman

2) Terus mencoba sesuatu yang baru, yaitu melakukan PTK dengan berbagai metode pembelajaran agar bermanfaat dalam menangani permasalahan-permasalahan siswa saat KBM berlangsung

\section{E. DAFTAR PUSTAKA}

Ahmad Rohani. (2004). Pengelolaan Pengajaran. Jakarta : PT Rineka Cipta

Depdikbud. (2003). Undang-Undang No. 20 Tahun 2003 tentang Sistem Pendidikan Nasional. Diambil dari http://www.dikti.go.id/files/atur/UU20-2003Sisdiknas.pdf tanggal 19 Oktober 2012.

Nana Sudjana. (2006). Dasar-dasar Proses belajar Mengajar. Bandung: Remaja Rosdakarya 
Jurnal Pendidikan Akuntansi Indonesia, Vol. XI, No. 2, Tahun 2013

Irfan Dwi Jayanto \& Sukirno

$1-10$

Nasution. (2000). Didaktik Asas-Asas Mengajar. Jakarta: Bumi Aksara.

Sardiman A. M. (2012). Interaksi \& Motivasi Belajar Mengajar. Jakarta. Rajawali Pers.

Sugiyono. (2012). Metode Penelitian Pendidikan. Bandung: Alfabeta.

Winataputra, Udin.S. 2007. Teori Belajar dan Pembelajaran. Jakarta: Universitas Terbuka

Wina Sanjaya. (2010). Strategi Pembelajaran Berorientasi Standar Proses Pendidikan. Jakarta: Kencana. 